\title{
Cortical Trajectory Screw Fixation in Lumbar Spine Surgery: A Review of the Existing Literature
}

\author{
Kun-Tae Kim ${ }^{1,2}$, Myung-Geun Song ${ }^{2}$, Young-Jin Park², Dong-Yeong Lee ${ }^{3}$, Dong-Hee Kim² \\ ${ }^{1}$ Regional Trauma Center, Gyeongsang National University Hospital, Jinju, Korea \\ ${ }^{2}$ Department of Orthopaedic Surgery and Institute of Health Science, Gyeongsang National University Hospital, \\ Gyeongsang National University College of Medicine, Jinju, Korea \\ ${ }^{3}$ Department of Orthopaedic Surgery and Joint Center, Barun Hospital, Jinju, Korea
}

\begin{abstract}
Posterior lumbar fusion is a safe and effective surgical method for diseases, such as lumbar stenosis, spondylolisthesis, lumbar instability, spinal deformity, and tumor. Pedicle screw (PS) fixation was first introduced by Bouche and has been adopted as the gold standard for posterior lumbar fusion. Santoni and colleagues introduced a new methodological screw insertion technique that uses a cortical bone trajectory (CBT), described as that from a medial to lateral path in the transverse axial plane and caudal to the cephalad path in the sagittal plane through the pedicle for maximum contact of the screw with the cortical bone. Owing to the lower invasiveness, superior cortical bone contact, and reduced neurovascular injury incidence, the CBT technique has been widely used in posterior lumbar fusion; however, these advantages have not been proven in clinical/radiological and biomechanical studies. We designed the present study to review the existing evidence and evaluate the merit of CBT screw fixation. Six electronic databases were searched for relevant articles published in August 2020 using the search terms "cortical bone trajectory," "CBT spine," "CBT fixation," "cortical pedicle screws," and "cortical screws." Studies were analyzed and divided into the following groups: "biomechanics investigation," "surgical technique," and "clinical/radiological studies." Most studies compared CBT and PS fixation, and the CBT screw fixation method showed better or similar outcomes.
\end{abstract}

Keywords: Pedicle screws; Cortical bone trajectory; Cortical screw; Pedicle screw; Lumbar fusion

\section{Introduction}

Posterior lumbar fusion is a safe and effective surgical method for diseases, such as lumbar stenosis, spondylolisthesis, lumbar instability, spinal deformity, and tumor [1-3]. Pedicle screw (PS) fixation was first introduced by Boucher [4] and has been adopted as the gold standard in posterior lumbar fusion [4]. This technique had shown good biomechanical strength and properties [5], superior correction, and non-union rate in patients with spinal deformity; however, PS fixation is also associated with certain limitations, such as dural tears, cerebrospinal fluid leakage, increased neurological or vascular injury risk and superior facet joint violation, wide muscle damage, larger intraoperative blood loss, and longer incision due to its lateral to medial trajectory [6-10]. Moreover,

Received Nov 11, 2020; Revised Dec 13, 2020; Accepted Dec 13, 2020

Corresponding author: Dong-Hee Kim

Department of Orthopaedic Surgery, Gyeongsang National University College of Medicine, 15 Jinju-daero 816beon-gil, Jinju 52727, Korea

Tel: +82-55-750-8669 (21), Fax: +82-55-761-9477 (22), E-mail: dhkim8311@gnu.ac.kr 
the maximum screw misplacement rate of PS fixation was $40 \%$ despite the use of navigation techniques [11-13]. In particular, PS fixation showed screw loosening, correction loss, and non-union in the osteoporotic bone [1416]. For more rigid fixation, various approaches, including the use of a different screw trajectory, have been presented with the focus of enhancing stability and preventing such complications [17]. The conventional pathway for the PS passes through the pedicle axis with a lateral to a medial path beginning at the cross line of the lateral border of the superior articular facet and line through the center of the transverse process (Fig. 1) [18]). In contrast, Santoni et al. [17] introduced a new methodological screw insertion technique via a cortical bone trajectory (CBT), described
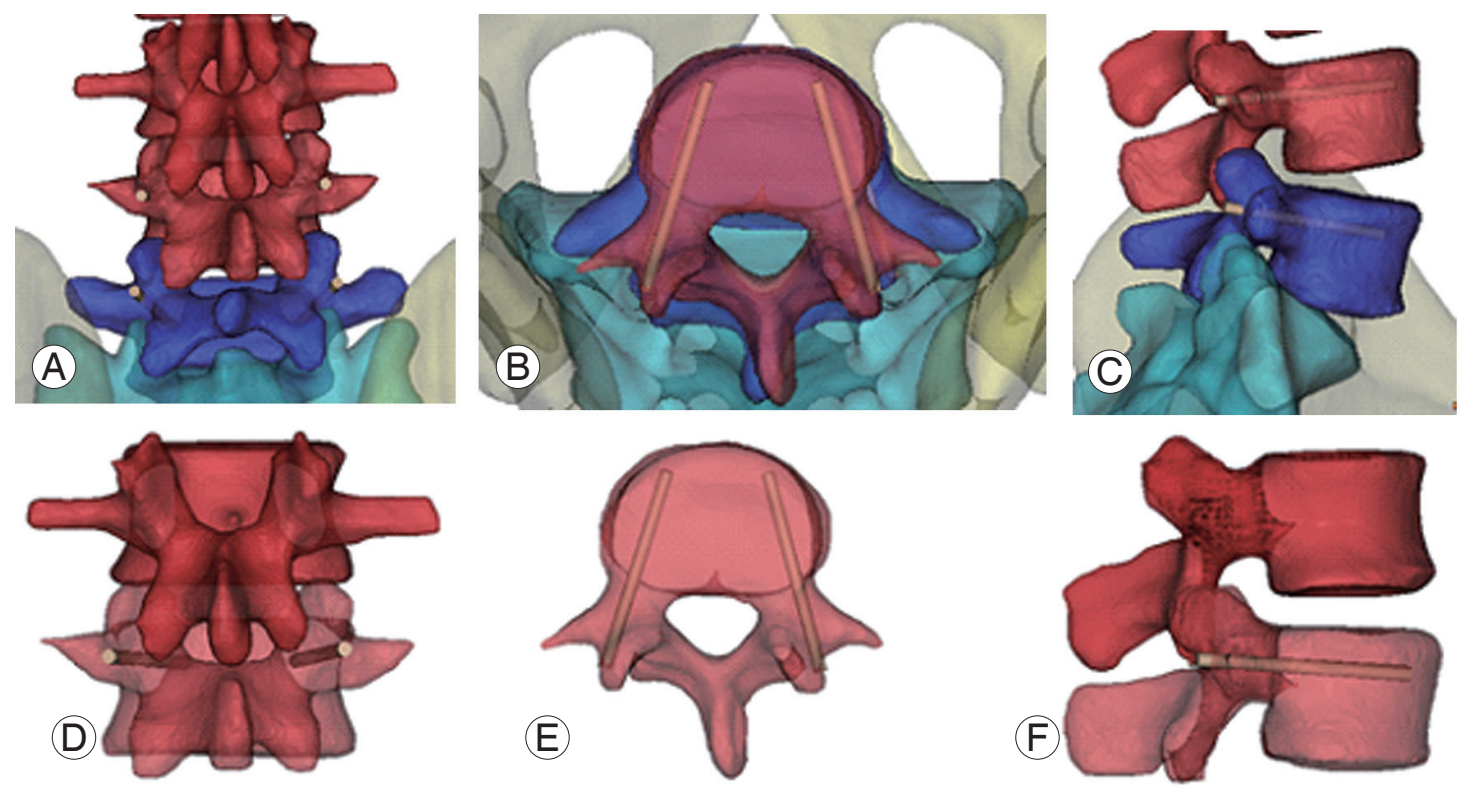

Fig. 1. Pedicle screw fixation (L4/5). (A, D) Entry point is cross line of lateral border of the superior articular facet and center of the transverse process. (B, E) Screw go through $15^{\circ}-25^{\circ}$ at transverse pedicle angle. (C, F) $L 4$ and $L 5$ sagittal pedicle angle is each $0^{\circ}, 5^{\circ}-10^{\circ}$ caudally declined.
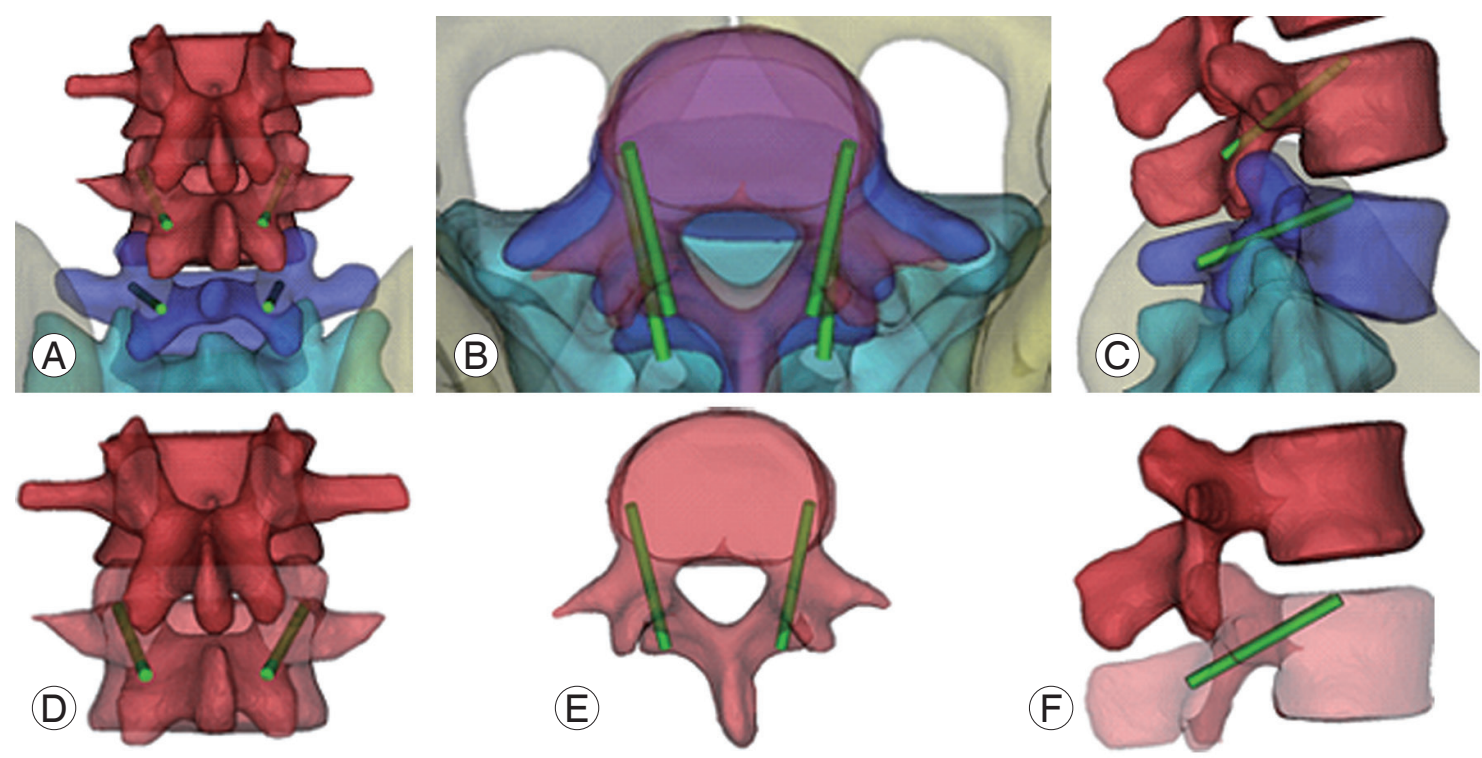

Fig. 2. Cortical bone trajectory screw fixation (L4/5). (A, D) Starting point is junction of the center of the superior articular process and $1 \mathrm{~mm}$ inferior to the inferior border of the transverse process. (B, E) Screw go through pedicle at medio-lateral pathway in transverse plane. (C, F) $25^{\circ}-30^{\circ}$ caudocranial pathway in sagittal plane. 
as that from medial to a lateral path in transverse axial plane and caudal to cephalad path in sagittal plane through the pedicle (Fig. 2) to secure greatest contact of the screw with cortical bone [19]. It may contribute to the stability in osteoporotic patients by increasing screw bone purchase unlike in PS fixation. Further, the medial starting point in the CBT screw fixation method involves minimal soft tissue dissection as compared with that in PS screw fixation and may lower the risk of neurovascular injury around the vertebrae. In the present review, we performed a comprehensive study of several articles to accumulate evidence regarding $\mathrm{CBT}$ screw fixation as an alternative technique in osteoporotic vertebrae for PS fixation.

\section{Methods}

MEDLINE, EMBASE, the Cochrane Central Register of Controlled Trials (CENTRAL), Web of Science, and SCOPUS electronic databases were searched for relevant articles published in August 2020 using the search terms "cortical bone trajectory," "CBT spine," "CBT fixation," "cortical pedicle screws," and "cortical screws." Studies were analyzed and divided into the following groups: "biomechanics investigation," "surgical technique," and "clinical/radiological studies." Full text articles and abstracts were included in the present review, whereas editorials and commentary texts were excluded.

\section{Biomechanical Characteristics}

In order to overcome the disadvantages of PS fixation in the osteoporotic bone, Santoni et al. [17] devised a CBT screw technique wherein the screw is fixed from the medial to the lateral path in the transverse plane, caudal to the cephalad path in the sagittal plane through the pedicle (Fig. 1). CBT screw fixation increases the holding screw strength by increasing the screw bone purchase power via modification of the thread pitch and shape and minimization of loosening that it showed a pullout and toggle character commensurate with PS [17]. An in vivo study reported 1.7 times higher insertion torque in CBT as compared with that in PS [20]. Although the maximal insertional torque and the correlation coefficient of bone mineral density (BMD) in the CBT technique were smaller than those in the PS technique, the maximal insertional torque was larger in the CBT group relatively fixed to the cortical bone less affected by osteoporosis [20].
Moreover, a finite element study showed higher resistance to flexion and extension loading in the CBT method and superior resistance to lateral bending and axial rotation in the PS method, irrespective of BMD owing to the emanant and short lever arms structure of CBT [21]. In several biomechanical and clinical studies, the CBT technique has shown good mechanical properties in terms of higher pullout strength and insertional torque, with similar stability of the screw rod construct as that with PS fixation [22-25]. Another in vivo study demonstrated that the CBT screw is affected by technical factors, such as the cephalad angle and screw length within the lamina and BMD; therefore, an appropriate insertion angle of $25^{\circ}-30^{\circ}$ cranially along the inferior border of the pedicle with sufficient length in the vertebral body and maximum contact to laminar is ideal [26]. In an animal experiment, the CBT technique showed similar biomechanical fixation as PS although shorter screws with a smaller diameter were used [25]. A cadaver study showed that CBT screw fixation had higher insertional torque, pullout strength, fatigue resistance, and load for displacing screws in the osteoporotic bone than PS fixation [27]. This issue remains debatable in patients with spondylolisthesis. CBT fixation in spondylolisthesis showed similar pullout strength as that using PS fixation; however, CBT screw fixation has lower cortical bone contact in the posterior lamina and short lever arm, with lower vertebral fixation strength than PS fixation in all planes of motion [23]. As per a radiological study, no significant differences were noted in the loss of slippage between the CBT and PS groups [28]. A cadaveric study also showed similar results at a multilevel lumbar segment with low-grade spondylolisthesis between the two groups. CBT fixation may have at least comparable biomechanical characteristics in reference to PS fixation [17,20-25,27-33] (Table 1). Different results may be obtained, depending on the surgical method. The CBT and PS methods showed no significant differences in stability as assessed using the range of motion (ROM) test (flexion, extension, lateral bending, and axial rotation) in direct lateral interbody fusion (DLIF). When performing the axial rotation test, the PS group had less ROM than the CBT group in transforaminal lumbar interbody fusion (TLIF) support [31]. In DLIF, greater cage insertion is possible than in TLIF, ensuring better stability to resist bending force. 


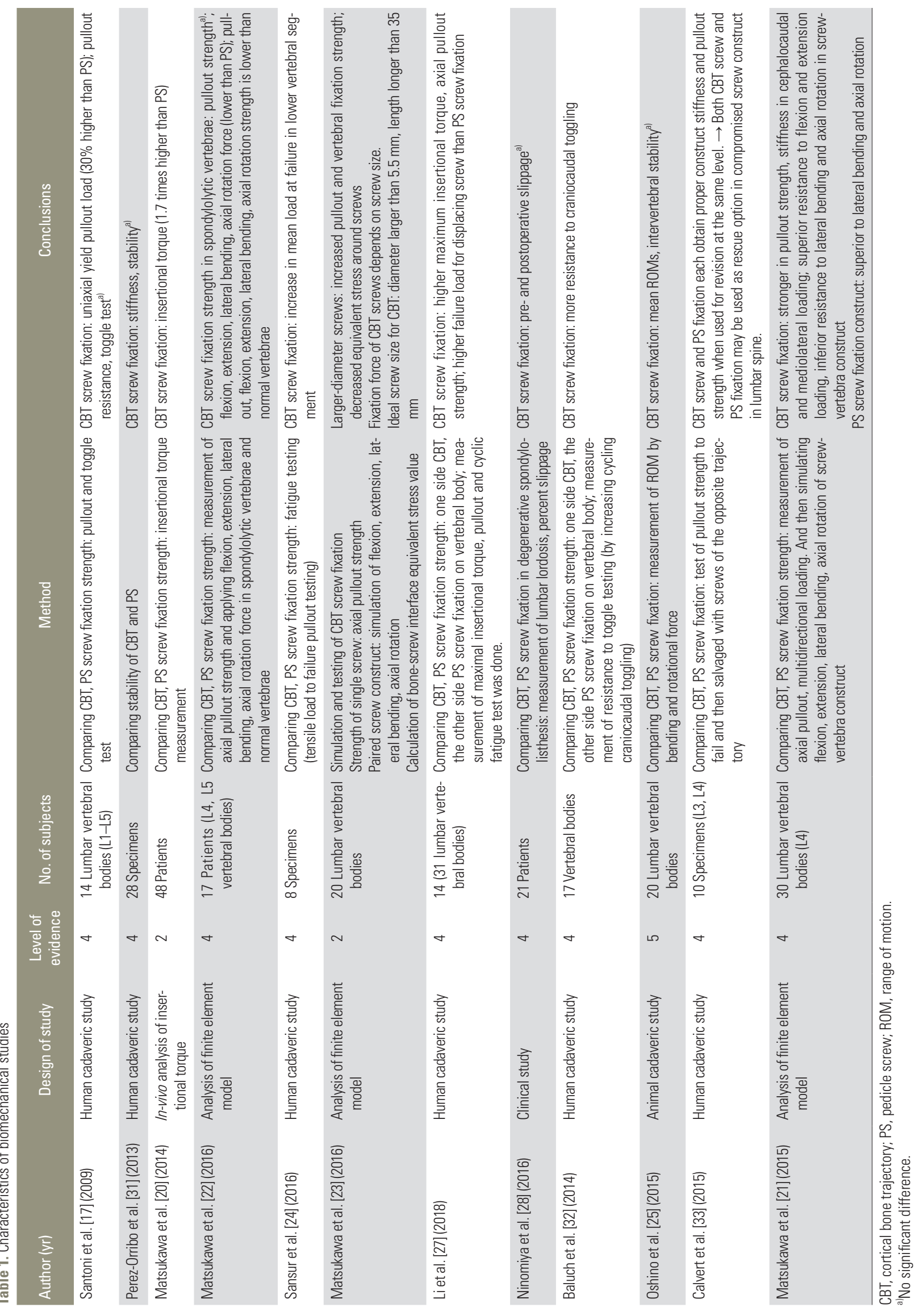




\section{Surgical Techniques}

First, Santoni et al. [17] introduced the new CBT that caudo-cephalad path in sagittal plane, mediolateral path in transverse plane for solid fixation to osteoporotic bone. Medio-latero-superior trajectory procedures for degenerative lumbar disease were proposed by Mobbs [34] with the use of a burr drill and proper tapping to prevent fracture of the pars, screw size, and rod diameter. In order to obtain detailed information about direction, screw size, and so on, Matsukawa et al. [19,20] performed morphometric measurement of the CBT. The starting point was defined at the junction of the center of the superior articular process and $1 \mathrm{~mm}$ inferior to the inferior border of the transverse process, at the 5 o'clock position of the left pedicle and 7 oclock position of the right pedicle radiographically. In vivo analysis showed that the ideal cortical trajectory was dependent on technical factors in which $25^{\circ}-30^{\circ}$ cranially along the inferior border of the pedicle in sagittal plane to get maximum purchase with the lamina [26]. Other strength tests confirmed that the laterally directed cortical screws have superior resistance in the transverse plane [32]. Matsukawa et al. [26] performed fixation toward the posterior third to the posterior half of the superior endplate through a $25^{\circ}-30^{\circ}$ cranially and $10^{\circ}$ laterally directed route. With respect to the size of the CBT screw, a three-dimensional (3D) finite element study showed that a screw larger than $5.5 \mathrm{~mm}$ and longer than $35 \mathrm{~mm}$ is appropriate for maximum contact to the lamina of the L4 vertebra [22]. Another morphometric study using computed tomography (CT) showed no significant difference between all pairs in terms of the maximum screw length in the axial plane; however, the maximum screw diameter in the axial plane showed a gradually increasing tendency from L1 to S1 of 4.8, 5.1, 6.1, 6.8, 8.0, and $6.1 \mathrm{~mm}$, respectively [35]. A study of the anatomic variations in CBT screw placement using preoperative CT reported favorable screw location, trajectory, and length, with improved outcomes and reduced complications [36]. In particular, the anatomic variations in each patient disturb the conventional trajectory [37]. A cadaver study that aimed to verify the accuracy and safety of the CBT screw using 3D patient-matched guide or navigation showed satisfactory results [37-39]. Moreover, primary clinical description of patient-matched guide for CBT screw fixation study showed improved accuracy and reduced the risk of nerve damage and reduced radiation exposure [40-42].

\section{Indications and Contraindications}

Generally, CBT screw fixation can be used for most lumbar spine disorders except severe spondylolysis and spinal deformity [43]. On the basis of evidence, indications for CBT screw fixation are described as follows. In osteoporosis, diminished fixation strength and increased screw loosening because of compromised trabecular bone are observed [16]. Osteoporotic changes have a greater effect on the cancellous bone than on the cortical bone. As PS fixation inserts screw anatomic axis of pedicle and depends on its stability with cancellous bone, CBT screw fixation firmly secures its contact between the screw thread and the cortical bone. In case of obese patients with a larger incision, minimally invasive surgery using the CBT technique is a good option because the medial starting point involves less muscle dissection [43]. Moreover, evaluation of the damage to the paraspinal muscle using CT scan indicated that the CBT technique was associated with less fat infiltration ratio, indicating less soft tissue injury [44]. As the CBT starting point on the pars interarticularis site that does not invade the superior facet joint [43], CBT screw fixation can lower the facet joint violation rates. This is in keeping with the result that CBT screw fixation significantly reduces symptomatic adjacent segment degeneration (ASD) and radiologic ASD as compared with PS fixation [45-47]. One of the reasons is that caudomedial entry point enables a reduction in the dissection of the superior facet joints [48]. Moreover, symptomatic ASD or screw failure with PS fixation requiring revision surgery can be indications for the use of the CBT technique. Thanks to different pathway of screw, CBT can be fixed and obtain proper stability without increasing screw size and length [33]. However, as per a meta-analysis, the revision rates in both the groups were comparable [49]. There are several contraindications for CBT screw fixation, and these contraindications have not been established [50]. Spondylolysis, described as a defect or stress fracture in pars interarticularis, should be excluded from indication [51]. CBT screw fixation depends on the force and stability on cortex of pars [52]. CBT is recommended in elderly patients with osteoporosis; however, elderly women and patients with spondylolysis with inadequate pars interarticularis should choose the surgical method, considering complications, such as screw loosening that may occur later [53]. In addition, the spondylolytic vertebra shows approximately $50 \%$ lower insertional torque (4.25 versus 8.24 in-lb [53]), 
$20 \%$ lower pullout strength, and 30\%-40\% lower vertebral fixation strength when compared with non-spondylolytic vertebra [22]. Other contraindication is severe spinal deformity with horizontal rotation. CBT screw fixation has a shorter trajectory; therefore, it does not have sufficient rotational stability to de-rotate the vertebra [16]. Moreover, congenital deformity of pars, narrow pars, lacks of cortical bone at pars due to wide decompression, iatrogenic pars fracture are contraindications. Regarding caudal fixation of S1, penetrating S1 endplate screw (PES) was presented [54]. The starting point of the PES is the intersection between the under 3-mm spot most endpoint of inferior articular facet of L5 and center line of L5/S1 articulating facet joint and the route is caudo-cephalad straight direction without convergence to infiltrate middle column of sacral endplate [54]. The PES is aimed at the lateral area of the sacrum with abundant trabecular bone for solid fixation; therefore, it showed higher insertional torque than that in the monocortical technique [55], was more resistant to loosening, and had higher pullout strength than S1-alar screws. The modified CBT screw technique in lumbosacral posterior lumbar interbody fusion (PLIF) showed a higher incidence of screw loosening at S1 than that in single-level fusion in spondylolisthesis. The entry point of the caudal screw was the medial margin of the pedicle on an articular surface of the superior articular process, and the track led from medial to lateral, parallel to the cephalad endplate [56].

\section{Clinical and Radiological Outcomes}

The clinical and radiological outcomes obtained using the CBT technique are similar to those achieved using PS fixation. As per a randomized control study [57], the fusion rates of both techniques were comparable (CBT 94.5\% versus PS 91.4\%, $p>0.99$ ) at 24 months postoperatively. $\mathrm{Pa}-$ tient satisfaction at 1 month was higher in the CBT group than in the PS fixation group (63\% versus $35 \%, p=0.03$ ); however, the Visual Analog Scale (VAS) leg pain score, the Oswestry Disability Index, and short form-12 score were not significantly different between the two groups. There were no significant differences in terms of screw loosening, infection, and recurrent radiating pain between the groups; however, facet joint violation was significantly lower in the CBT group (0\% versus $18 \%, p<0.01$ ) [57,58]. Comparative studies showed better results in terms of perioperative pain and Japanese Orthopaedic Associa-
Table 2. Outcomes of meta-analysis studies

\begin{tabular}{|c|c|c|c|}
\hline Variable & $\begin{array}{l}\text { Zhang et al. [67] } \\
\qquad(2019)\end{array}$ & $\begin{array}{l}\text { Wang et al. [49] } \\
\qquad(2019)\end{array}$ & $\begin{array}{l}\text { Hu et al. [65] } \\
\qquad(2019)\end{array}$ \\
\hline Fusion rate & NSD & NSD & NSD \\
\hline Back pain VAS & NSD & NSD & NSD \\
\hline Leg pain VAS & NSD & NSD & NSD \\
\hline JOA score & NSD & NSD & NSD \\
\hline JOA recovery rate & NM & C & NM \\
\hline Patients' satisfaction & C & C & NM \\
\hline Incidence of reoperation & NM & NSD & NM \\
\hline Operation time & C & C & NM \\
\hline Intraoperative blood loss & C & C & C \\
\hline Length of hospital day & C & C & C \\
\hline Incidence of complications & $C^{a)}$ & NM & $\mathrm{NSD}^{\mathrm{b})}$ \\
\hline ASD & C & C & NM \\
\hline Oswestry Disability Index & C & C & NSD \\
\hline $\begin{array}{l}\text { Incidence of superior facet } \\
\text { joint violation }\end{array}$ & NM & C & NM \\
\hline Wound infection & NM & NSD & NM \\
\hline Screw malposition & NM & NSD & NM \\
\hline Incision length & NM & C & C \\
\hline
\end{tabular}

NSD, no significant difference; VAS, Visual Analog Scale; JOA score, Japanese Orthopaedic Association score; NM, not mentioned; C, superior outcomes in cortical bone trajectory; ASD, adjacent segment degeneration.

a)Dural tear, screw dislocation, hematoma, wound infection, ASD, cage subsid-

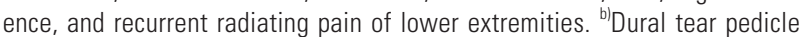
fracture, screw malposition, hematoma, wound infection, and ASD.

tion (JOA) Back Pain Evaluation Questionnaire social life function scores at 1 month, with similar improvement in the JOA score [59]. Regarding complications, the prevalence of symptomatic adjacent segment disease was lower in the CBT group than in the PS group (3\% versus $11 \%$, $p<0.05)[46,47]$. Other studies have shown similar fusion rates, JOA scores, radiographic fusion, and intraoperative and postoperative complications in patients with osteoporosis, with lower rates of screw loosening (6.5\% versus $28.13 \%, p=0.03)[60,61]$. A systematic review and metaanalysis also showed less external bleeding loss, intraoperative muscle damage, and perioperative pain, with faster recovery to normal activities in the CBT group (Table 2) [29].

\section{Complications}

Several studies have reported the intraoperative/postoperative complications $[58,62,63]$. Screw loosening, neuro- 
logical deficits, infections, vascular injuries, cerebrospinal fluid leak due to dural laceration, wound dehiscence, urinary retention, and screw malposition were observed; however, but there were no differences in the complications between the CBT and PS groups. With respect to ASD, symptomatic ASD and patients who needed additional surgical intervention for ASD were higher in the PS group [45-47]. Furthermore, radiologic ASD increased in the PS-PLIF group owing to the risk of proximal facet joint violation that caused destabilization at the supraadjacent segment. Pars interarticularis and pedicle frac- tures may occur in the osteoporotic bone when setting the starting point. A high-speed round burr drill can help in lowering the risk of pars fracture [34].

\section{Clinical Application of the Cortical Bone Trajectory Technique}

A 75-year-old woman with osteoporosis who had been taking bisphosphonate for 10 years presented with a complaint of low back pain radiating to both the extremities, accompanied by intermittent claudication that had per-
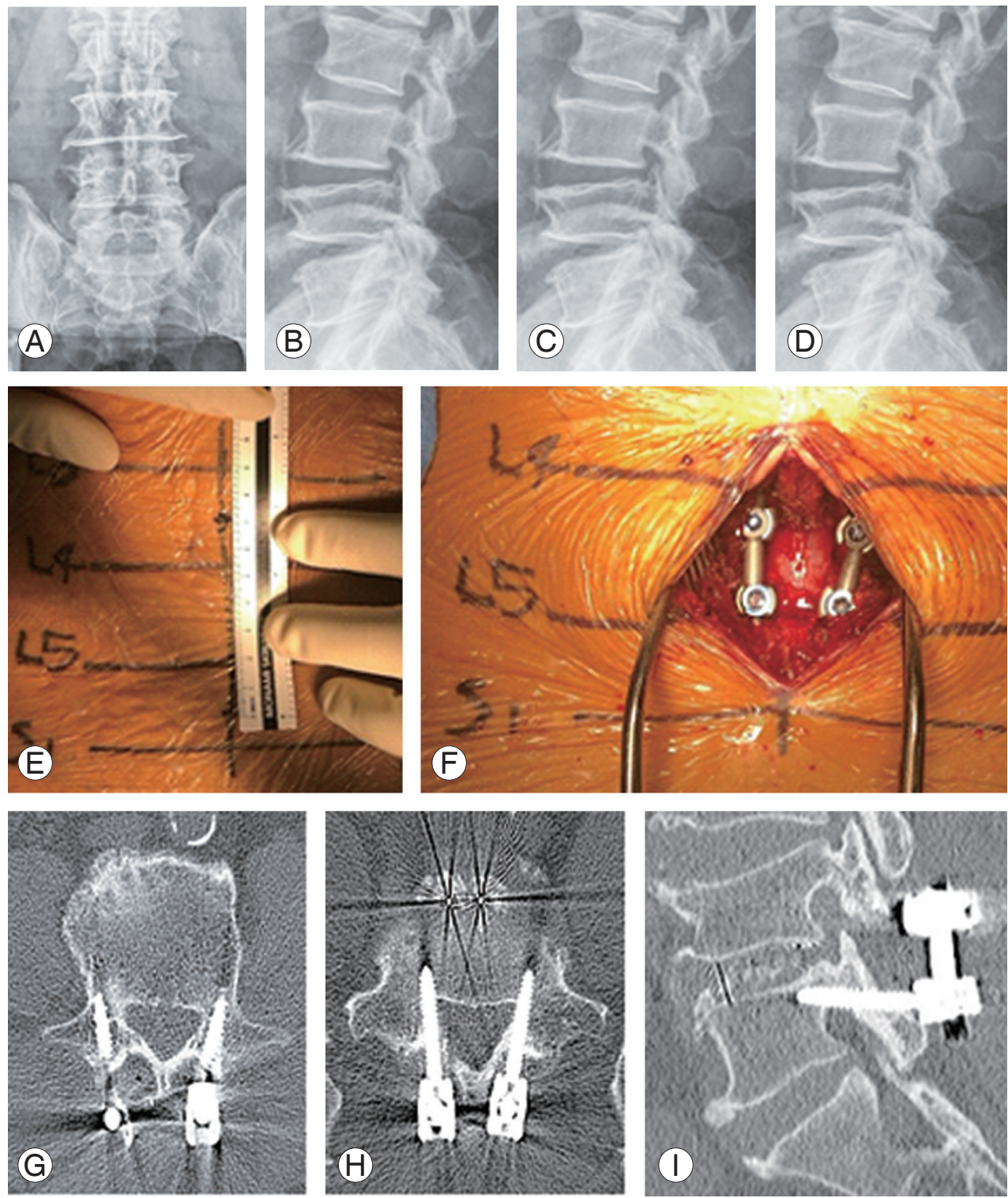

Fig. 3. (A, B) Preoperative L-spine anterior-posterior (AP), lateral X-ray. (C, D) Postoperative L-spine AP, lateral X-ray. (E, F) Intraoperative X-ray. (G-I) Postoperative computed tomography. 
sisted for 3 years and had aggravated 1 month previously. Conservative treatment (physiotherapy and medication) did not relieve her chief complaint. Imaging studies showed central stenosis involving L4/5. Considering patient age and bone quality, PLIF using CBT screw fixation method was performed. In order to reduce bleeding and muscle damage, we made a smaller incision (approximately $7 \mathrm{~cm}$ ) and performed muscle dissection rather than PS screw fixation. Her back pain and neurogenic claudication reduced postoperatively. Preoperative and postoperative plain radiography and CT scans showed good CBT screw placement (Fig. 3).

\section{Discussion}

Several surgical approaches have been introduced for posterior lumbar fusion. The most widely used PS screw fixation involves less contact with the higher-density cortical bone and requires a larger exposure to fix the screw. The invitation of CBT screws, some drawbacks of PS fixation may be reformed. Thinner threads and shorter screw design, pathway of CBT screws make greater contact and support pullout strength for stability in osteoporotic patients. Regarding the caudomedial entry point, the CBT screw can be placed more medially than the PS screw [64]. This involved less dissection of the facet joints and the paraspinal muscles. Minimization of muscle damage using the CBT method is related to less postoperative pain and good functional recovery with a shorter hospital stay [44]. Moreover, it can reduce the possibility of pedicle medial wall perforation, neural injury risk, and facet joint violation [30]. Accordingly, less blood loss and pain can be expected in the immediate postoperative setting [58], and other studies have revealed superior outcomes with the use of the CBT technique $[49,65,66]$. From the perspective of fusion rates, the two groups were not significantly different [49,65,67]; however, Sakaura et al. [47] reported higher fusion rates in the PS group. It could be attributed to stronger stiffness against axial rotation and lateral bending when TLIF fusion is performed with PS fixation [31]. The micromotion resulting from CBT fixation with weaker stiffness than that with PS might cause an early cyclic loading failure and influence the fusion rate [68]. When PS screw placement fails or the pedicle is too small for screw fixation, CBT screw fixation can also be used as a salvage method. Considering the advantages of the CBT technique, it can be an alternative to PS fixation; however, there is insufficient evidence from few long-term studies on the use of the CBT technique. In terms of complications, the CBT technique showed a lower overall incidence than PS fixation. Complications are predictable through entry point and trajectory of CBT technique. Preoperative imaging study can reduce the complications by predicting the pathway of the screws and spondylosis including pars interarticularis defect and checking bone density with BMD. Entry point and trajectory have not been defined well owing to the possibilities of being excluded severe degenerative change of the anatomy of lumber spine. Given any typical or atypical pars interarticularis caused by degenerative change, fluoroscopy-guided CBT screw fixation may not always allow simple and exact placement of the screw. However, these limitations can be resolved with the use of a technological method such as 3D-printed patientspecific guide or navigation. With technological advances, the customized trajectory for diverse anatomy of a single patient may become possible for maximum cortical bone contact and achieving the biomechanical advantage of the CBT screw. As such, the CBT technique is evolving to achieve secure excellent cortical bone contact and optimal trajectory. The CBT technique is not proven to be superior to PS fixation in all aspects in previous clinical, radiological, and biomechanical studies, and various methods have been suggested for safer and more reliable CBT fixation. Santoni et al. [17] first introduced CBT, and many studies have reported on its application and short-term outcomes. However, crucial in vivo data on prerequisites for inserting interbody for proper fixation have been published recently $[31,68,69]$. In addition, the CBT method might be technically challenging. Loss of reduction at the 1-year follow-up [70], direct loosening of all the screws on imaging, and loss of reduction despite intraoperative $\mathrm{O}$-arm confirmation have been reported [68]. Moreover, the fusion rate as well as back and leg VAS score were similar in meta-analysis $[49,65,67]$. Although there are advantages of the CBT technique, a careful literature review is necessary. The present review has the following limitations. Most studies included in this review were retrospective case series of case-control studies. In vivo biomechanical results, definitive surgical indications and contraindications, and patient-related clinical/radiological outcomes and complications require further examination [44-47,5759,61-63,71-75] (Table 3). For successful CBT fixation, the following guideline has been proposed. Imaging studies should be used for checking the screw trajectory, entry 


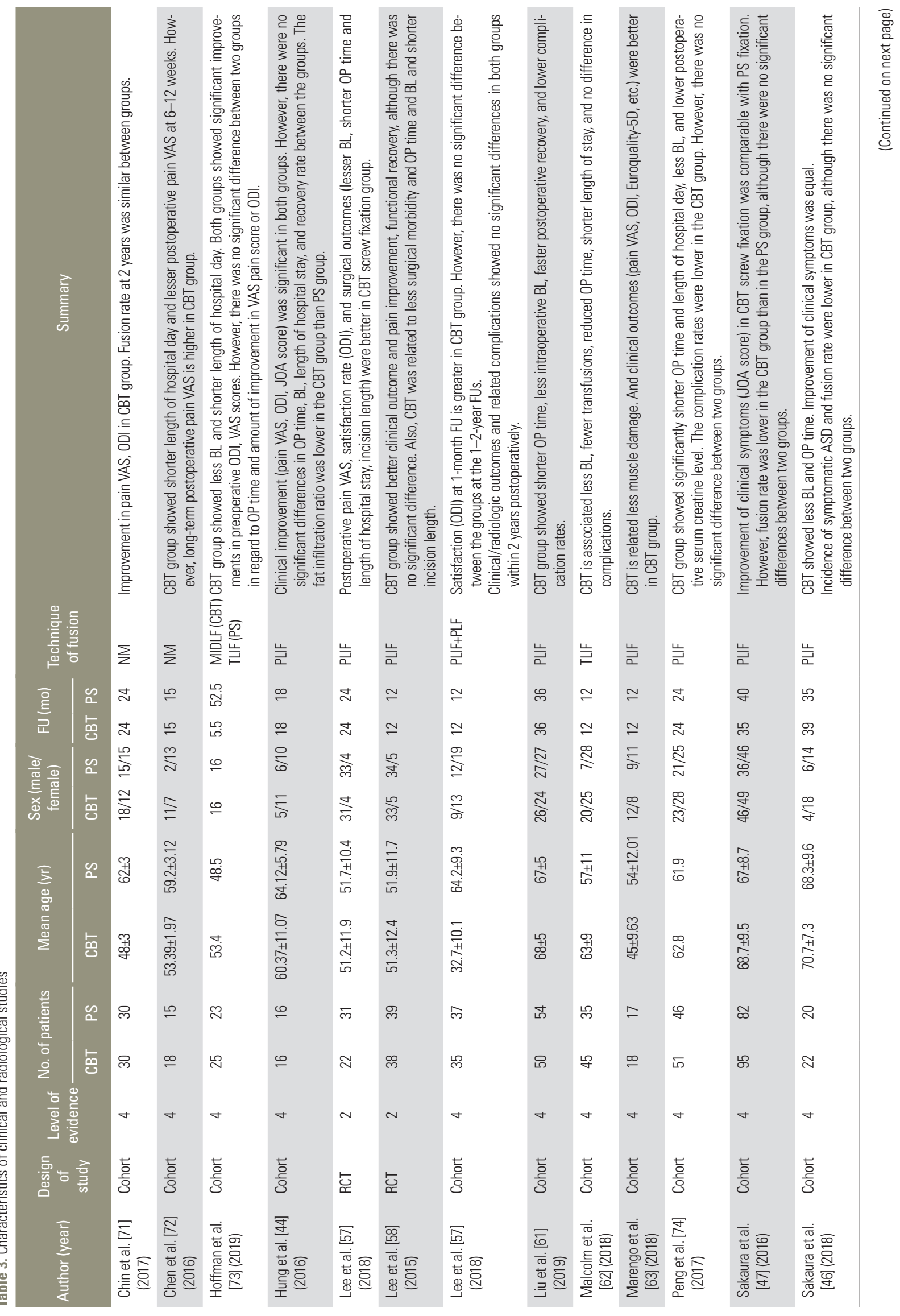




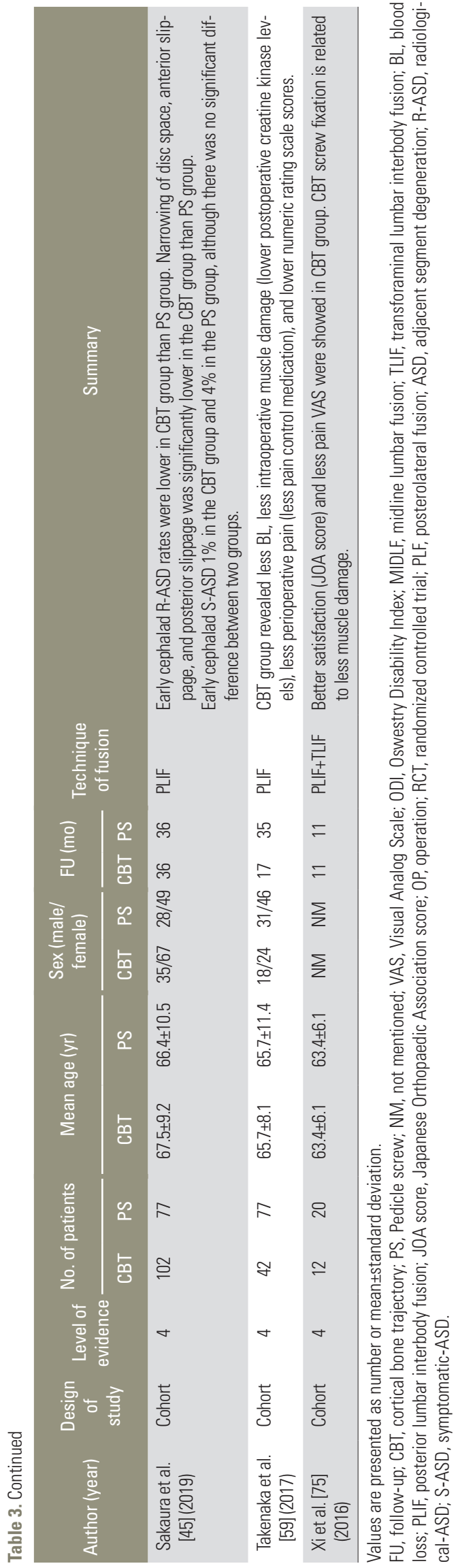

point, and spondylosis. If the pars interarticularis is not intact, PS fixation should be considered. Insertion of 5.5 mm diameter and $30-40 \mathrm{~mm}$ length screw on the way to $25^{\circ}-30^{\circ}$ cranially, $10^{\circ}$ laterally toward posterior half of superior endplate [22]. Transverse rod connector can be an option to prevent micromotion that causes screw loosening or a lower fusion rate than that of the PS method $[47,68]$.

\section{Conclusions}

CBT screw fixation has been verified to be an effective and safe technique in lumbar surgery. Biomechanical studies showed similar or better results with the CBT technique than with fixation, depending on factors, such as screw position, size, and length. Clinical and radiologic outcomes showed equal or better results in the fusion rates, patient satisfaction, functional recovery, and complication incidence. Securing stability via maximal cortical bone contact is a major feature of the CBT technique; however, it is not applicable in all patients. The CBT technique is not always superior in biomechanical tests, and long-term follow-up results are yet to be reported. Thus, the CBT method is a safe and stable option for fusion, and surgery methods should be selected considering the patients' condition.

\section{Conflict of Interest}

No potential conflict of interest relevant to this article was reported.

\section{ORCID}

Kun-Tae Kim: https://orcid.org/0000-0003-4610-4238; Myung-Geun Song: https://orcid.org/0000-0003-4330-3645; Young-Jin Park: https://orcid.org/0000-0001-5644-9235; Dong-Yeong Lee: https://orcid.org/0000-0001-6894-2684; Dong-Hee Kim: https://orcid.org/0000-0001-6378-4218

\section{References}

1. Bydon M, De la Garza-Ramos R, Macki M, Baker A, Gokaslan AK, Bydon A. Lumbar fusion versus nonoperative management for treatment of discogenic low back pain: a systematic review and meta-analysis of randomized controlled trials. J Spinal Disord Tech 
2014;27:297-304.

2. Chen Q, Brahimaj BC, Khanna R, et al. Posterior atlantoaxial fusion: a comprehensive review of surgical techniques and relevant vascular anomalies. J Spine Surg 2020;6:164-80.

3. Moskowitz A. Transforaminal lumbar interbody fusion. Orthop Clin North Am 2002;33:359-66.

4. Boucher HH. A method of spinal fusion. J Bone Joint Surg Br 1959;41-B:248-59.

5. Roy-Camille R, Saillant G, Mazel C. Plating of thoracic, thoracolumbar, and lumbar injuries with pedicle screw plates. Orthop Clin North Am 1986;17:14759.

6. Babu R, Park JG, Mehta AI, et al. Comparison of superior-level facet joint violations during open and percutaneous pedicle screw placement. Neurosurgery 2012;71:962-70.

7. Herren C, Reijnen M, Pishnamaz M, et al. Incidence and risk factors for facet joint violation in open versus minimally invasive procedures during pedicle screw placement in patients with trauma. World Neurosurg 2018;112:e711-8.

8. Mehta VA, McGirt MJ, Garces Ambrossi GL, et al. Trans-foraminal versus posterior lumbar interbody fusion: comparison of surgical morbidity. Neurol Res 2011;33:38-42.

9. Mobbs RJ, Sivabalan P, Li J. Technique, challenges and indications for percutaneous pedicle screw fixation. J Clin Neurosci 2011;18:741-9.

10. Rao PJ, Maharaj MM, Phan K, Lakshan Abeygunasekara M, Mobbs RJ. Indirect foraminal decompression after anterior lumbar interbody fusion: a prospective radiographic study using a new pedicle-topedicle technique. Spine J 2015;15:817-24.

11. Weinstein JN, Spratt KF, Spengler D, Brick C, Reid S. Spinal pedicle fixation: reliability and validity of roentgenogram-based assessment and surgical factors on successful screw placement. Spine (Phila Pa 1976) 1988;13:1012-8.

12. Laine T, Lund T, Ylikoski M, Lohikoski J, Schlenzka D. Accuracy of pedicle screw insertion with and without computer assistance: a randomised controlled clinical study in 100 consecutive patients. Eur Spine J 2000;9:235-40.

13. Gertzbein SD, Robbins SE. Accuracy of pedicular screw placement in vivo. Spine (Phila Pa 1976) 1990;15:11-4.
14. Brantley AG, Mayfield JK, Koeneman JB, Clark KR. The effects of pedicle screw fit: an in vitro study. Spine (Phila Pa 1976) 1994;19:1752-8.

15. Frankel BM, D’Agostino S, Wang C. A biomechanical cadaveric analysis of polymethylmethacrylateaugmented pedicle screw fixation. J Neurosurg Spine 2007;7:47-53.

16. Hirano T, Hasegawa K, Takahashi HE, et al. Structural characteristics of the pedicle and its role in screw stability. Spine (Phila Pa 1976) 1997;22:2504-9.

17. Santoni BG, Hynes RA, McGilvray KC, et al. Cortical bone trajectory for lumbar pedicle screws. Spine J 2009;9:366-73.

18. Vieweg U, Grochulla F. Manual of spine surgery. Berlin: Springer Science \& Business Media; 2012.

19. Matsukawa K, Yato Y, Nemoto O, Imabayashi H, Asazuma T, Nemoto K. Morphometric measurement of cortical bone trajectory for lumbar pedicle screw insertion using computed tomography. J Spinal Disord Tech 2013;26:E248-53.

20. Matsukawa K, Yato Y, Kato T, Imabayashi H, Asazuma T, Nemoto K. In vivo analysis of insertional torque during pedicle screwing using cortical bone trajectory technique. Spine (Phila Pa 1976) 2014;39:E240-5.

21. Matsukawa K, Yato Y, Imabayashi H, Hosogane N, Asazuma T, Nemoto K. Biomechanical evaluation of the fixation strength of lumbar pedicle screws using cortical bone trajectory: a finite element study. J Neurosurg Spine 2015;23:471-8.

22. Matsukawa K, Yato Y, Imabayashi H, et al. Biomechanical evaluation of fixation strength among different sizes of pedicle screws using the cortical bone trajectory: what is the ideal screw size for optimal fixation? Acta Neurochir (Wien) 2016;158:465-71.

23. Matsukawa K, Yato Y, Imabayashi H, Hosogane N, Asazuma T, Chiba K. Biomechanical evaluation of lumbar pedicle screws in spondylolytic vertebrae: comparison of fixation strength between the traditional trajectory and a cortical bone trajectory. J Neurosurg Spine 2016;24:910-5.

24. Sansur CA, Caffes NM, Ibrahimi DM, et al. Biomechanical fixation properties of cortical versus transpedicular screws in the osteoporotic lumbar spine: an in vitro human cadaveric model. J Neurosurg Spine 2016;25:467-76.

25. Oshino H, Sakakibara T, Inaba T, Yoshikawa T, Kato 
T, Kasai Y. A biomechanical comparison between cortical bone trajectory fixation and pedicle screw fixation. J Orthop Surg Res 2015;10:125.

26. Matsukawa K, Taguchi E, Yato Y, et al. Evaluation of the fixation strength of pedicle screws using cortical bone trajectory: what is the ideal trajectory for optimal fixation? Spine (Phila Pa 1976) 2015;40:E873-8.

27. Li HM, Zhang RJ, Gao H, et al. Biomechanical fixation properties of the cortical bone trajectory in the osteoporotic lumbar spine. World Neurosurg 2018;119:e717-27.

28. Ninomiya K, Iwatsuki K, Ohnishi Y, Yoshimine T. Radiological evaluation of the initial fixation between cortical bone trajectory and conventional pedicle screw technique for lumbar degenerative spondylolisthesis. Asian Spine J 2016;10:251-7.

29. Phan K, Ramachandran V, Tran TM, et al. Systematic review of cortical bone trajectory versus pedicle screw techniques for lumbosacral spine fusion. J Spine Surg 2017;3:679-88.

30. Delgado-Fernandez J, Garcia-Pallero MA, Blasco G, Pulido-Rivas P, Sola RG. Review of cortical bone trajectory: evidence of a new technique. Asian Spine J 2017;11:817-31.

31. Perez-Orribo L, Kalb S, Reyes PM, Chang SW, Crawford NR. Biomechanics of lumbar cortical screw-rod fixation versus pedicle screw-rod fixation with and without interbody support. Spine (Phila $\mathrm{Pa} 1976$ ) 2013;38:635-41.

32. Baluch DA, Patel AA, Lullo B, et al. Effect of physiological loads on cortical and traditional pedicle screw fixation. Spine (Phila Pa 1976) 2014;39:E1297-302.

33. Calvert GC, Lawrence BD, Abtahi AM, Bachus KN, Brodke DS. Cortical screws used to rescue failed lumbar pedicle screw construct: a biomechanical analysis. J Neurosurg Spine 2015;22:166-72.

34. Mobbs RJ. The "medio-latero-superior trajectory technique": an alternative cortical trajectory for pedicle fixation. Orthop Surg 2013;5:56-9.

35. Zhang H, Ajiboye RM, Shamie AN, Wu Q, Chen Q, Chen W. Morphometric measurement of the lumbosacral spine for minimally invasive cortical bone trajectory implant using computed tomography. Eur Spine J 2016;25:870-6.

36. Senoglu M, Karadag A, Kinali B, Bozkurt B, Middlebrooks EH, Grande AW. Cortical bone trajectory screw for lumbar fixation: a quantitative anatomic and morphometric evaluation. World Neurosurg 2017;103:694-701.

37. Kaito T, Matsukawa K, Abe Y, Fiechter M, Zhu X, Fantigrossi A. Cortical pedicle screw placement in lumbar spinal surgery with a patient-matched targeting guide: a cadaveric study. J Orthop Sci 2018;23:865-9.

38. Wang K, Zhang ZJ, Chen JX, Wu AM, Wang XY, Sheng SR. Design and application of individualized, 3-dimensional-printed navigation template for placing cortical bone trajectory screws in middle-upper thoracic spine: cadaver research study. World Neurosurg 2019;125:e348-52.

39. Kim SB, Rhee JM, Lee GS, Lee HY, Kim T, Won Y. Computer-assisted patient-specific prototype template for thoracolumbar cortical bone trajectory screw placement: a cadaveric study. Tech Orthop 2018;33:246-50.

40. Marengo N, Matsukawa K, Monticelli M, et al. Cortical bone trajectory screw placement accuracy with a patient-matched 3-dimensional printed guide in lumbar spinal surgery: a clinical study. World Neurosurg 2019;130:e98-104.

41. Solomiichuk V, Fleischhammer J, Molliqaj G, et al. Robotic versus fluoroscopy-guided pedicle screw insertion for metastatic spinal disease: a matchedcohort comparison. Neurosurg Focus 2017;42:E13.

42. Molliqaj G, Schatlo B, Alaid A, et al. Accuracy of robot-guided versus freehand fluoroscopy-assisted pedicle screw insertion in thoracolumbar spinal surgery. Neurosurg Focus 2017;42:E14.

43. Matsukawa K, Yato Y. Lumbar pedicle screw fixation with cortical bone trajectory: a review from anatomical and biomechanical standpoints. Spine Surg Relat Res 2017;1:164-73.

44. Hung CW, Wu MF, Hong RT, Weng MJ, Yu GF, Kao $\mathrm{CH}$. Comparison of multifidus muscle atrophy after posterior lumbar interbody fusion with conventional and cortical bone trajectory. Clin Neurol Neurosurg 2016;145:41-5.

45. Sakaura H, Ikegami D, Fujimori T, et al. Early cephalad adjacent segment degeneration after posterior lumbar interbody fusion: a comparative study between cortical bone trajectory screw fixation and traditional trajectory screw fixation. J Neurosurg Spine 2019;32:155-9.

46. Sakaura H, Miwa T, Yamashita T, Kuroda Y, Ohwada 
T. Cortical bone trajectory screw fixation versus traditional pedicle screw fixation for 2-level posterior lumbar interbody fusion: comparison of surgical outcomes for 2-level degenerative lumbar spondylolisthesis. J Neurosurg Spine 2018;28:57-62.

47. Sakaura H, Miwa T, Yamashita T, Kuroda Y, Ohwada T. Posterior lumbar interbody fusion with cortical bone trajectory screw fixation versus posterior lumbar interbody fusion using traditional pedicle screw fixation for degenerative lumbar spondylolisthesis: a comparative study. J Neurosurg Spine 2016;25:591-5.

48. Matsukawa K, Kato T, Yato Y, et al. Incidence and risk factors of adjacent cranial facet joint violation following pedicle screw insertion using cortical bone trajectory technique. Spine (Phila Pa 1976) 2016;41:E8516.

49. Wang J, He X, Sun T. Comparative clinical efficacy and safety of cortical bone trajectory screw fixation and traditional pedicle screw fixation in posterior lumbar fusion: a systematic review and meta-analysis. Eur Spine J 2019;28:1678-89.

50. Kolz JM, Pinter ZW, Bydon M, Sebastian AS. Controversies in spine surgery: is a cortical bone trajectory superior to traditional pedicle screw trajectory? Clin Spine Surg 2020 Mar 20 [Epub]. https://doi. org/10.1097/BSD.0000000000000965.

51. Iwamoto J, Takeda T, Wakano K. Returning athletes with severe low back pain and spondylolysis to original sporting activities with conservative treatment. Scand J Med Sci Sports 2004;14:346-51.

52. Weiner BK, Walker M, Wiley W, McCulloch JA. The lateral buttress: an anatomic feature of the lumbar pars interarticularis. Spine (Phila Pa 1976) 2002;27:E385-7.

53. Ninomiya K, Iwatsuki K, Ohnishi YI, Ohkawa T, Yoshimine T. Significance of the pars interarticularis in the cortical bone trajectory screw technique: an in vivo insertional torque study. Asian Spine J 2016;10:901-6.

54. Matsukawa K, Yato Y, Kato T, Imabayashi H, Asazuma T, Nemoto K. Cortical bone trajectory for lumbosacral fixation: penetrating S-1 endplate screw technique: technical note. J Neurosurg Spine 2014;21:203-9.

55. Ebraheim N, Sabry FF, Nadim Y, Xu R, Yeasting RA. Internal architecture of the sacrum in the elderly: an anatomic and radiographic study. Spine (Phila Pa
1976) 2000;25:292-7.

56. Sakaura H, Miwa T, Yamashita T, Kuroda Y, Ohwada T. Fixation strength of caudal pedicle screws after posterior lumbar interbody fusion with the modified cortical bone trajectory screw method. Asian Spine J 2016;10:639-45.

57. Lee GW, Ahn MW. Comparative study of cortical bone trajectory-pedicle screw (cortical screw) versus conventional pedicle screw in single-level posterior lumbar interbody fusion: a 2-year post hoc analysis from prospectively randomized data. World Neurosurg 2018;109:e194-202.

58. Lee GW, Son JH, Ahn MW, Kim HJ, Yeom JS. The comparison of pedicle screw and cortical screw in posterior lumbar interbody fusion: a prospective randomized noninferiority trial. Spine J 2015;15:151926.

59. Takenaka S, Mukai Y, Tateishi K, Hosono N, Fuji T, Kaito T. Clinical outcomes after posterior lumbar interbody fusion: comparison of cortical bone trajectory and conventional pedicle screw insertion. Clin Spine Surg 2017;30:E1411-8.

60. Elmekaty M, Kotani Y, Mehy EE, et al. Clinical and radiological comparison between three different minimally invasive surgical fusion techniques for single-level lumbar isthmic and degenerative spondylolisthesis: minimally invasive surgical posterolateral fusion versus minimally invasive surgical transforaminal lumbar interbody fusion versus midline lumbar fusion. Asian Spine J 2018;12:870-9.

61. Liu L, Zhang S, Liu G, Yang B, Wu X. Early clinical outcome of lumbar spinal fixation with cortical bone trajectory pedicle screws in patients with osteoporosis with degenerative disease. Orthopedics 2019;42:e465-71.

62. Malcolm JG, Moore MK, Choksh FH, Ahmad FU, Refai D. Comparing cortical trajectory transforaminal lumbar interbody fusions against pedicle trajectory transforaminal lumbar interbody fusions and posterolateral fusions: a retrospective cohort study of 90-day outcomes. Neurosurgery 2018;83:1234-40.

63. Marengo N, Ajello M, Pecoraro MF, et al. Cortical bone trajectory screws in posterior lumbar interbody fusion: minimally invasive surgery for maximal muscle sparing: a prospective comparative study with the traditional open technique. Biomed Res Int 2018;2018:7424568. 
64. Mizuno M, Kuraishi K, Umeda Y, Sano T, Tsuji M, Suzuki H. Midline lumbar fusion with cortical bone trajectory screw. Neurol Med Chir (Tokyo) 2014;54:716-21.

65. Hu JN, Yang XF, Li CM, Li XX, Ding YZ. Comparison of cortical bone trajectory versus pedicle screw techniques in lumbar fusion surgery: a meta-analysis. Medicine (Baltimore) 2019;98:e16751.

66. Zhang GA, Zhang WP, Chen YC, Hou Y, Qu W, Ding LX. Efficacy of vertebroplasty in short-segment pedicle screw fixation of thoracolumbar fractures: a meta-analysis. Med Sci Monit 2019;25:9483-9.

67. Zhang T, Guo N, Chen T, Yan J, Zhao W, Xu G. Comparison of outcomes between cortical screws and traditional pedicle screws for lumbar interbody fusion: a systematic review and meta-analysis. J Orthop Surg Res 2019;14:269.

68. Glennie RA, Dea N, Kwon BK, Street JT. Early clinical results with cortically based pedicle screw trajectory for fusion of the degenerative lumbar spine. J Clin Neurosci 2015;22:972-5.

69. Kaye ID, Prasad SK, Vaccaro AR, Hilibrand AS. The cortical bone trajectory for pedicle screw insertion. JBJS Rev 2017;5:e13.

70. Mori K, Nishizawa K, Nakamura A, Imai S. Shortterm clinical result of cortical bone trajectory technique for the treatment of degenerative lumbar spon- dylolisthesis with more than 1-year follow-up. Asian Spine J 2016;10:238-44.

71. Chin KR, Pencle FJR, Coombs AV, et al. Clinical outcomes with midline cortical bone trajectory pedicle screws versus traditional pedicle screws in moving lumbar fusions from hospitals to outpatient surgery centers. Clin Spine Surg 2017;30:E791-7.

72. Chen YR, Deb S, Pham L, Singh H. Minimally invasive lumbar pedicle screw fixation using cortical bone trajectory: a prospective cohort study on postoperative pain outcomes. Cureus 2016;8:e714.

73. Hoffman H, Verhave B, Jalal MS, Beutler T, Galgano MA, Chin LS. Comparison of cortical bone trajectory screw placement using the midline lumbar fusion technique to traditional pedicle screws: a case-control study. Int J Spine Surg 2019;13:33-8.

74. Peng J, Zhan Y, Liu Y, Zong Y, Mao Y. Comparison of effectiveness of cortical bone trajectory screw fixation and pedicle screw fixation in posterior lumbar interbody fusion. Zhongguo Xiu Fu Chong Jian Wai Ke Za Zhi 2017;31:1341-5.

75. Xi YH, Wang Y, Yu JM, Liu XL, Xie N, Ye XY. Curative effect of cortical bone trajectory screw combined with pedicle screw in internal fixation for senile osteoporosis lumbar degenerative disease. Acad J Second Mil Med Univ 2016;37:879-83. 